
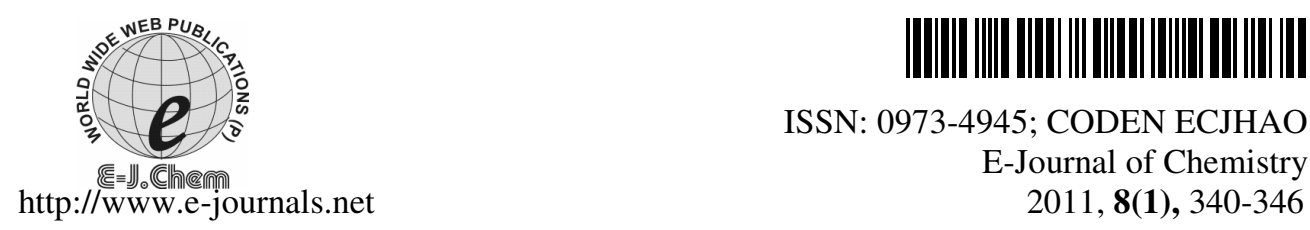

ISSN: 0973-4945; CODEN ECJHAO

E-Journal of Chemistry 2011, 8(1), 340-346

\title{
Simultaneous Determination of Preservatives (Methyl Paraben and Propyl Paraben) in Sucralfate Suspension Using High Performance Liquid Chromatography
}

\author{
RAJESH M. KAMBLE*, SANTOSH G. SINGH \\ and SHRAWAN SINGH \\ Department of Chemistry, University of Mumbai \\ Vidyanagari, Santacruz (East), Mumbai- 400 098, India \\ chemrajkam@yahoo.co.in
}

Received 11 May 2010; Accepted 20 July 2010

\begin{abstract}
A reversed phase HPLC method that allows the separation and simultaneous determination of the preservatives methyl paraben (M.P.) and propyl paraben (P.P.) is described. The separations were effected by using an initial mobile phase of water: acetonitrile (50:50) on Inertsil C18 to elute P.P. and M.P. The detector wavelength was set at $205 \mathrm{~nm}$. Under these conditions, separation of the two components was achieved in less than $10 \mathrm{~min}$. Analytical characteristics of the separation such as precision, specificity, linear range and reproducibility were evaluated. The developed method was applied for the determination of preservative M.P. and P.P. at concentration of $0.01 \mathrm{mg} / \mathrm{mL}$ and $0.1 \mathrm{mg} / \mathrm{mL}$ respectively. The method was successfully used for determining both compounds in sucralfate suspension.
\end{abstract}

Keywords: Methyl paraben, Propyl paraben, HPLC, Preservatives.

\section{Introduction}

Pharmaceutical preparations which need an aqueous vehicle such as syrups and powders for oral suspensions require safeguards from microbial contamination, which may affect product stability or infect the consumers. This is accomplished by the addition of anti-microbial agents in the formulation to destroy and inhibits the growth of those organisms that may contaminate the product during manufacture or use ${ }^{1}$. The international committee of harmonization $(\mathrm{ICH})$ guidelines $^{2}$ requests that for submission of drug registration dossier on dry powders for oral suspensions, data should be provided for the content of the active pharmaceutical ingredient (API) as well as the type(s) and amount(s) of the preservatives(s) used. 
In addition, the efficacy of the antimicrobial preservation should be demonstrated by challenging the reconstituted in its final container with specified microorganism. Sources of this microbial contamination may include air and water, manufacturing equipment, manufacturing personnel or the consumer ${ }^{3}$.

Bacterial contamination of the products through consumers use has resulted in presence of mixed and harmful microbial flora in the product ${ }^{4}$. Several chemical preservative agents exist and have been widely employed in the cosmetic, food and pharmaceutical industries ${ }^{4}$. For oral use, the choices of the preservatives are limited, which are generally effective to control mould and yeast growth. These include $p$-hydroxybenzoic acid esters: methyl paraben (M.P.) $\mathrm{C}_{6} \mathrm{H}_{4}(\mathrm{OH}) \mathrm{COOCH}_{3}$ and propyl paraben (P.P.) $\mathrm{C}_{6} \mathrm{H}_{4}(\mathrm{OH}) \mathrm{COOC}_{3} \mathrm{H}_{7}$, which are most commonly used to control bacterial growth due to their broad antimicrobial spectrum with good stability and non-volatility ${ }^{5}$. M.P and P.P. are usually used in combination as they possess a synergistic activity when used together. However, overuse of preservatives may cause allergic reactions hence, they should be shown not to be cytotoxic or sensitizing ${ }^{6,7}$.

$p$-Hydroxybenzoic esters (parabens) have been used as preservatives for over 70 years $^{8}$. Parabens are the most commonly used since they have synergistic effects ${ }^{9}$. However, it contains esters of longer alkyl chains which limit its applications due to lower solubility in water ${ }^{10}$. Literature survey reveals few HPLC methods described for the determination of M.P. and P.P. along with other substances in different oral suspensions ${ }^{11-14}$ and in food stuffs ${ }^{15}$. However there is no RP-HPLC method reported for the simulations determination of these two preservatives in sucralfate oral suspension. The purpose of the present study was to develop a speedily and sensitive method for the simultaneous determination of M.P. and P.P. using HPLC/UV.

\section{Experimental}

Acetonitrile (HPLC grade), S.D. Fine chemicals, Methanol (HPLC grade), S.D. Fine chemicals, Water (HPLC grade), formic acid (Merck grade) were used throughout the experiment.

\section{Chromatographic conditions}

Chromatographic separations were performed with Thermo electron corporation high performance liquid chromatography having pump series P-2000 HPLC isocratic pump and detector UV/VIS, series UV-1000. Chromatographic separations of active (M.P. and P.P.) were obtained by using Intersil C18 column $(250 \times 4.6 \mathrm{~mm}, 5 \mu \mathrm{m}$ particle size $)$. Mobile phase was mixture of water: acetonitrile $(50: 50 \mathrm{v} / \mathrm{v})$. Filtered through a $0.45 \mu \mathrm{m}$ nylon filter and degassed for $5 \mathrm{~min}$ in an ultrasonicator. The mobile phase was pumped through the column at flow rate of $1.0 \mathrm{~mL} / \mathrm{min}$. Analyses were carried out at $25{ }^{\circ} \mathrm{C}$ temperature with detection at $205 \mathrm{~nm}$. The injection volume was $20 \mu \mathrm{L}$ and each analysis required $10 \mathrm{~min}$. The peaks elute of M.P. and P.P was approximate at 5.0, 9.0 min respectively.

\section{Preparation of blank solution}

$5 \mathrm{~mL}$ of methanol mixed with $5 \mathrm{~mL}$ of $50 \%$ formic acid and diluted to $100 \mathrm{~mL}$ with methanol.

Preparation of standard stock solution of P.P.

Stock solution of P.P. $0.2 \mathrm{mg} / \mathrm{mL}$ was prepared by dissolving $20 \mathrm{mg}$ of P.P. working standard in a $100 \mathrm{~mL}$ volumetric flask with methanol.

\section{Preparation of standard solution}

Standard solution $0.01 \mathrm{mg} / \mathrm{mL}$ and $0.1 \mathrm{mg} / \mathrm{mL}$ of M.P. and P.P was prepared respectively by dissolving $20 \mathrm{mg}$ of M.P. with $10 \mathrm{~mL}$ of $50 \%$ formic acid in $200 \mathrm{~mL}$ volumetric flask. $10 \mathrm{~mL}$ of standard stock solution of P.P was added to it and diluted up to the volume with methanol. 


\section{Preparation of sample solution}

Sample solution of sucralfate was prepared by dissolving $5.0 \mathrm{~g}$ of suspension with $5 \mathrm{~mL}$ of $50 \%$ formic acid and finally made up to volume with methanol. Sample solution was then filtered through $0.45 \mu \mathrm{m}$ filter paper.

\section{Validation of proposed method}

The assay of the preservatives methyl paraben and propyl paraben was validated with respect to linearity, precision and accuracy, robustness and stability.

\section{Calibration curve (linearity)}

Accurately measured aliquots of working standard solutions equivalent to $0.05-0.15 \mathrm{mg} / \mathrm{mL}$ M.P. and $0.005-0.015 \mathrm{mg} / \mathrm{mL}$ P.P. were transferred to 2 series of $100 \mathrm{~mL}$ volumetric flasks and the contents of the flasks were diluted to volume with diluents. A $20 \mu \mathrm{L}$ aliquot of each solution was injected in triplicate. The conditions including the flow rate of mobile phase at $1.0 \mathrm{~mL} / \mathrm{min}$, detection at $205 \mathrm{~nm}$ and run time program for about $15.0 \mathrm{~min}$, were adjusted. A calibration curve for each preservative was obtained by plotting area response versus concentration which gave a straight line corresponding to the equation: $\mathrm{y}=\mathrm{mx}+\mathrm{c}$ as shown in Figure 1 .

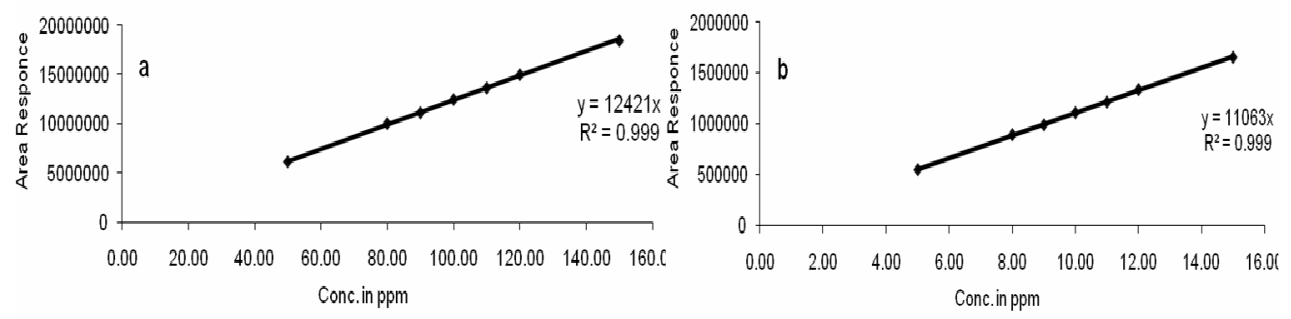

Figure 1. Linearity of (a) methyl paraben and (b) propyl paraben

\section{Accuracy (\% recovery)}

The accuracy of the methods was determined by calculating recoveries of M.P. and P.P. by the standard addition method. Known amounts of standard solutions of M.P. (0.05, 0.1 and $0.15 \mathrm{mg} / \mathrm{mL}$ ) and P.P. $(0.005,0.01$ and $0.015 \mathrm{mg} / \mathrm{mL})$ were added to prequantified sample solutions. The amounts of M.P. and P.P were estimated by applying these values to the regression equations of the calibration curves. The recovery obtained did not differ from the real value $( \pm 2.0 \%)$.

\section{Filter paper saturation}

The minimum volume of sample solution required for saturating the filter paper was checked. The results of two successive filtrations using compatible filter paper should not differ by $2.0 \%$. The results obtained are summarized in Table 1 .

\section{Filter paper compatibility}

The method used to check the compatibility of filter paper for sample solution to be filtered. The obtained results using filter paper were compared with results obtained with centrifuged sample. Results obtained after using filtration does not differ by $2.0 \%$ with respect to centrifuged sample. The results are shown in Table 1. 
Table 1. Validation parameters

\begin{tabular}{lll}
\hline Parameter & \multicolumn{2}{c}{ \% RSD } \\
\hline & M.P. & P.P. \\
Filter paper saturation & 0.12 & 0.12 \\
Filter paper compatibility & 0.12 & 0.12 \\
\hline
\end{tabular}

\section{Robustness}

The robustness of the method is its ability to remain unaffected by small changes in parameters. Experiments were carried under variable parameters such as flow rate, mobile phase composition, $\mathrm{pH}$ of the mobile phase buffer solution and column oven temperature. Flow rate varied at three levels $(0.8,1.0$ and 1.2), change in composition of mobile phase water: Acetonitrile (48:52, 50:50 and 52:48), change in column oven temperature $\left(22{ }^{\circ} \mathrm{C}, 25^{\circ} \mathrm{C}\right.$ and $28{ }^{\circ} \mathrm{C}$ ), change in different brand of filter paper. Thus two replicate injections of standard solution at same concentration levels were performed. Absolute difference between $\%$ assay under altered condition and mean \% assay obtained during repeatability was not more than $2.0 \%$.

\section{Specificity}

Specificity is the ability of the analytical method to measure analyte response in presence of interferences including related substances. Specificity was checked by determining M.P. and P.P. in binary mixture.

\section{Solution Stability test}

The stability of standard solution and sample solution was compared with data of absolute difference in percent assay at each interval with respect to initial values of M.P. and P.P. A binary solution of standard and sample solution of concentration $0.1 \mathrm{mg} / \mathrm{mL}$ for M.P and $0.01 \mathrm{mg} / \mathrm{mL}$ for P.P. was used. The standard and sample solution were stored at room temperature and analyzed over the time period of initial, $12 \mathrm{~h}$ and $24 \mathrm{~h}$. The absolute difference between $\%$ assay values was not more than $\pm 2.0 \%$ compared to the initial value.

\section{Method precision (repeatability)}

The instrumental precision was checked by repeatedly injecting $(\mathrm{n}=6)$ solution of binary mixture containing M.P. $(0.1 \mathrm{mg} / \mathrm{mL})$ and P.P $(0.01 \mathrm{mg} / \mathrm{mL})$ on same day.

\section{Intermediate precision (reproducibility)}

The interday precisions of the proposed method was determined by estimating the corresponding responses $(n=6)$ times on different days for same concentrations of M.P. $(0.1 \mathrm{mg} / \mathrm{mL})$ and P.P. $(0.010 \mathrm{mg} / \mathrm{mL})$. The results are reported in terms of relative standard deviation (RSD). \% RSD for twelve sample preparations (six of intraday and six of interday precision) was not more than $2.0 \%$.

\section{Results and Discussion}

The absorption spectra of M.P. and P.P. greatly overlap; so conventional determination of these compounds in mixture is not possible. To overcome this problem the HPLC/UV method was utilized for the present study. To optimize the LC parameters, several mobile phase compositions were tried. A satisfactory separation and good peak symmetry for M.P. and P.P. was obtained with a mobile phase consisting of water: Acteonitrile $(50: 50 \mathrm{v} / \mathrm{v})$. Quantification of the drugs was performed at $205 \mathrm{~nm}$. Resolution of the components with clear baseline separation was obtained (Figure 2). 


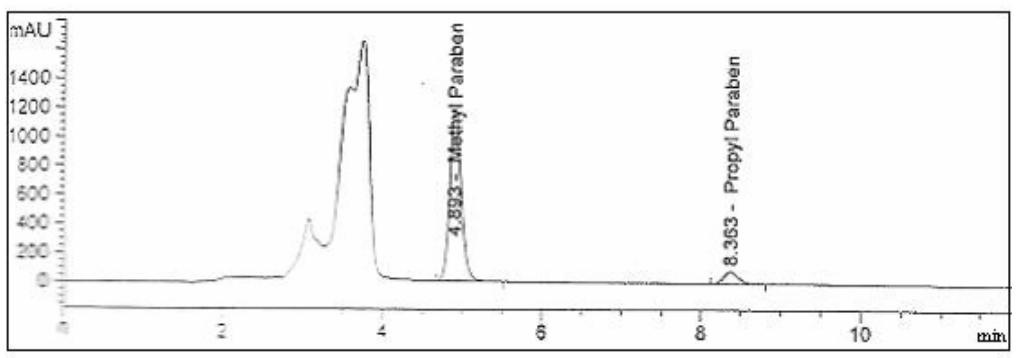

Figure 2. Method precision of methyl paraben and propyl paraben

The linearity of calibration curves was validated, and correlation coefficients of regression were found near to 1 (Table 2). The results showed that good correlation existed between the peak area and concentration of the analytes.

The recoveries obtained were (98.4-100.0) \% and (98.3-101.0) \% for M.P. and P.P. respectively. The high values indicate that the method was accurate. The RSD values for M.P. and P.P. in combined formulations were found to be 0.19 and $0.17 \%$ respectively (Table 2). The low RSD values indicate that the proposed method is repeatable. The intermediate precision RSD values for M.P and P.P. were 0.25 and $0.47 \%$ respectively. The $\% \operatorname{RSD}(<2 \%)$ values indicate that the method was sufficiently precise (Table 2 ).

The absence of interference between drugs determined is shown in Table 2. Moreover the proposed method was applied to a pharmaceutical formulation containing two drugs under study. The standard addition technique was used to assess the accuracy of proposed method. Satisfactory results were obtained indicating the high specificity of proposed method for determination of P.P and M.P. in binary mixtures. Six replicate injections of standard solution were measured at the beginning of each analysis for system suitability. The relative standard deviation (\%RSD) obtained with responses was less than $2.0 \%$ (Table 2) which indicates the repeatability (method precision) of the proposed method.

Table 2. Calibration curve

\begin{tabular}{|c|c|c|}
\hline Parameter & M.P. & P.P. \\
\hline Linearity coefficient & 0.99971 & 0.99983 \\
\hline Precision \% RSD & 0.19 & 0.17 \\
\hline Intermediate precision & 0.25 & 0.47 \\
\hline Solution stability \%RSD $12 \mathrm{~h}$ & 0.12 & 0.20 \\
\hline $24 \mathrm{~h}$ & 0.15 & 0.17 \\
\hline Specificity $\%$ RSD & 0.12 & 0.20 \\
\hline
\end{tabular}

\section{Filter paper compatibility}

The standard and sample solutions were divided into two parts. One part of the solution, one part of solution was centrifuged and other part of solution was filtered through different types of filter papers such as Whatman no. 41, Whatman no. 42, Whatman GF/C and $0.45 \mu \mathrm{m}$ nylon filter papers. The absolute difference of the results for filtered solutions through different types of filter paper and centrifuged were not more than 2.0.

\section{Filter paper saturation}

At the stage of filtration, the sample stock solution was filtered through $0.45 \mu$ nylon filter paper. First, $7 \mathrm{~mL}$ of sample solution was filtered and the filtrate was collected in first test tube. Again second aliquot of $7 \mathrm{~mL}$ sample solution was filtered through the same saturated 
filter paper and the filtrate was collected in second test tube. The filtrate of third aliquot of $7 \mathrm{~mL}$ sample solution was collected in third test tube using the same saturated filter paper. These collected filtrates were analyzed after discarding $0.0 \mathrm{~mL}, 7.0 \mathrm{~mL}$ and $14.0 \mathrm{~mL}$. It was found that absolute difference of the $\%$ assay results between two successive filtrations was not more than $2.0 \%$ (Figure 3 ).

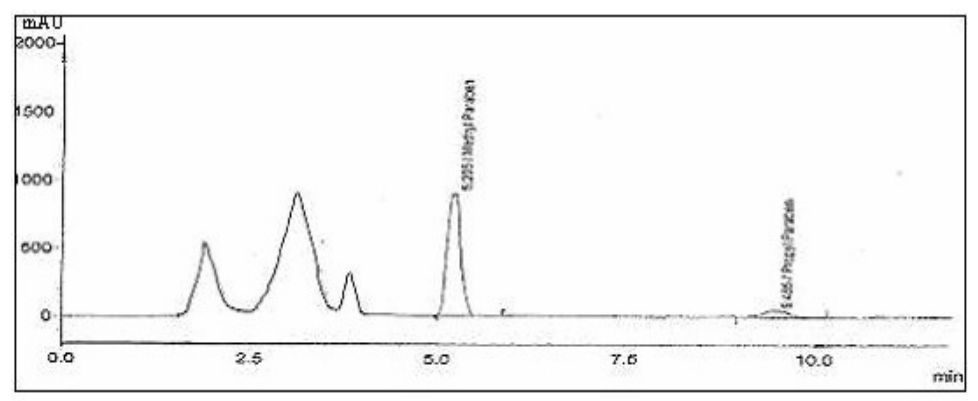

Figure 3. Filter paper saturation at $7 \mathrm{~mL}$

\section{Robustness}

Effect of change in flow rate, change in temperature of column oven, change in concentration of mobile phase and mobile phase stability were applied as variable parameters. Flow rate varied at three levels $(0.8,1.0$ and 1.2$) \mathrm{mL} / \mathrm{min}$, change in column oven temperatures at $\left(22{ }^{\circ} \mathrm{C}, 25{ }^{\circ} \mathrm{C}\right.$ and $\left.28{ }^{\circ} \mathrm{C}\right)$ and change in composition of mobile phase water: acetonitrile $(48: 52,50: 50$ and 52:48). One factor at a time was changed to estimate the effect. Thus replicate injections $(n=3)$ of standard solution at same concentration levels were performed under small changes of two chromatographic parameters (factors). Results presented in Table 3 indicate that the selected factors remained unaffected by small variation of these parameters. It was also found that there is no significant influence on retention time by change in such parameters and insignificant variability in retention time was observed.

Table 3. Robustness evaluation of proposed HPLC method

\begin{tabular}{lccc}
\hline \multicolumn{1}{c}{ Chromatographic change Factor } & Level & \multicolumn{2}{c}{$\%$ RSD } \\
\hline \multirow{2}{*}{ A: Flow rate, $\mathrm{mL} / \mathrm{min}$} & 0.8 & 0.15 & 0.24 \\
& 1.0 & 0.12 & 0.20 \\
& 1.2 & 0.26 & 0.23 \\
B: Column temperature & $22^{\circ} \mathrm{C}$ & 0.10 & 0.14 \\
& $25^{\circ} \mathrm{C}$ & 0.12 & 0.20 \\
C: Water : ACN & $28^{\circ} \mathrm{C}$ & 0.48 & 0.47 \\
& $(48: 52)$ & 0.28 & 0.22 \\
D: Mobile phase stability & $(50: 50)$ & 0.12 & 0.20 \\
& $(52: 48)$ & 0.27 & 0.26 \\
& --- & 0.24 & 0.22 \\
\hline
\end{tabular}

\section{Conclusion}

The sample pre-treatment procedure, in combination with the HPLC method was found to be suitable for the determination of methyl paraben and propyl paraben which acts as a preservative in drug items. The proposed method presented in this paper has advantages of simplicity, accuracy, precision and convenience for separation of M.P. and P.P. and can be used for the assay of their respective dosage form. The method is also fast as it requires 
approximately 10 minutes for analysis. Thus, the proposed LC method can be used for the quality control of M.P. and P.P in typical laboratories. The validation parameters were also found in acceptable of FDA and ICH guidelines.

\section{References}

1. European pharmacopoeia IV European Directorate for the quality of medicines for the council of Europe, Strasbourg, 2003.

2. International committee on Harmonization: Specifications and control tests on the finished product, Directive 75/ 318/ EEC, 1992.

3. Anger C B, Rupp D and Lo P, Preservation of Dispersed Systems in Pharmaceutical dosage forms, $2^{\text {nd }}$ Ed., Marcel Dekker, New York, 1996.

4. Wilson L A, Kuehne J W, Hall S W and Ahear D G, Am J Ophthalmol., 1971, 71, 1298-1302.

5. The Japanese standards of cosmetic ingredients-with commentary In the Society of Japanese Pharmacopoeia, $2^{\text {nd }}$ Ed., Yakuginippousha, Tokyo, 1984.

6. Soni M G, Burdock G A, Taylor S L and Greenberg N A, Food Chem Toxicol., 2001, 39, 513-532.

7. Klocker N, Kramer A, Verse T, Sikora C, Rudolph P and Daeschlein G, Eur J Pharmaceut Biopharmaceut., 2004, 57, 489-493.

8. Hajkova R, Solich P, Pospisilova M and Sicha J, Anal Chem Acta, 2002, 467, 91-96.

9. Mahuzier P E, Altria K D and Clark B J, J Chromatogr A, 2001, 924, 465-470.

10. Kuo K L and Hsieh Y Z, J Chromatogr A, 1997, 768, 334-341.

11. Diane K and Bela K, J Chromatogr B: Biomed Sci Appl., 1998, 707(1-2), 181-187.

12. Akhtar M J, Khan S, Roy I M and Jafri I A, J Pharm Biomed Anal., 1996, 14, 1609-1613.

13. Kokoletsi M X, Kafkala S and Tsiaganis M, J Pharm Biomed Anal., 2005, 38, 763-767.

14. Ali M S, Chaudhary R S and Takieddin M A, Drug Develop Ind Pharm., 1999, 25, 1143-1147.

15. Saad B, Bari M F, Saleh M I, Ahmad K and Talib M K M, J Chromatogr A., 2003, 1073, 393-397. 


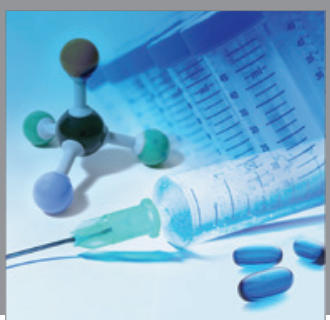

International Journal of

Medicinal Chemistry

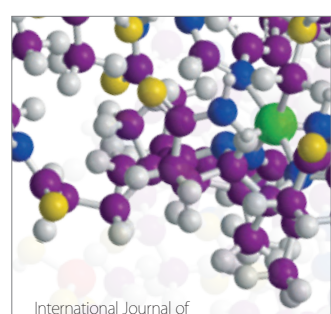

Carbohydrate Chemistry

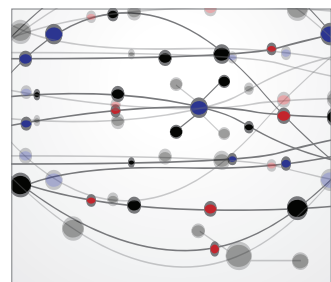

The Scientific World Journal
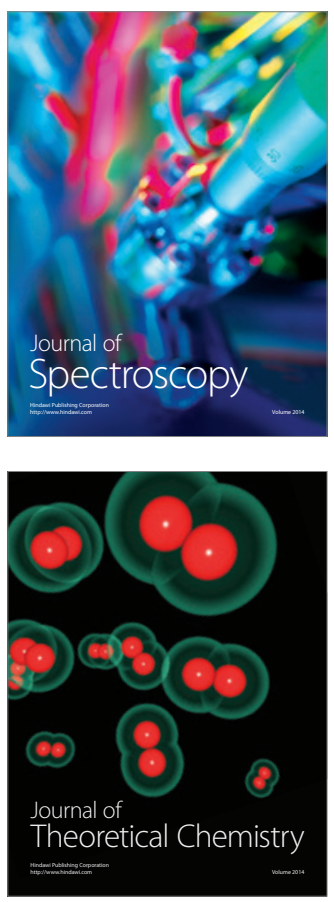
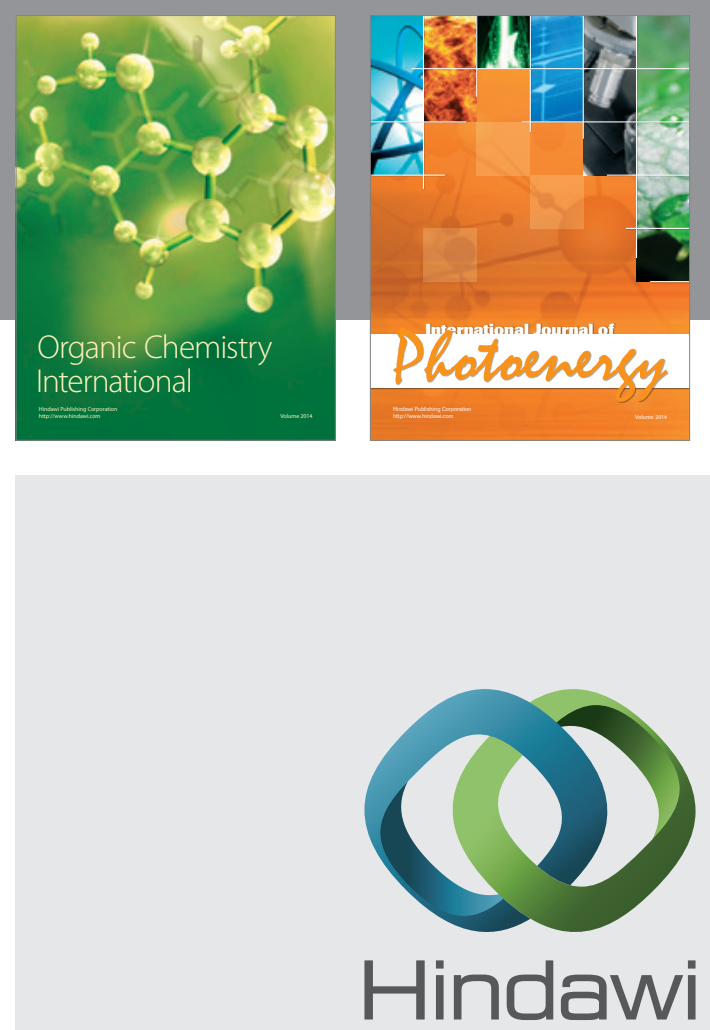

Submit your manuscripts at

http://www.hindawi.com
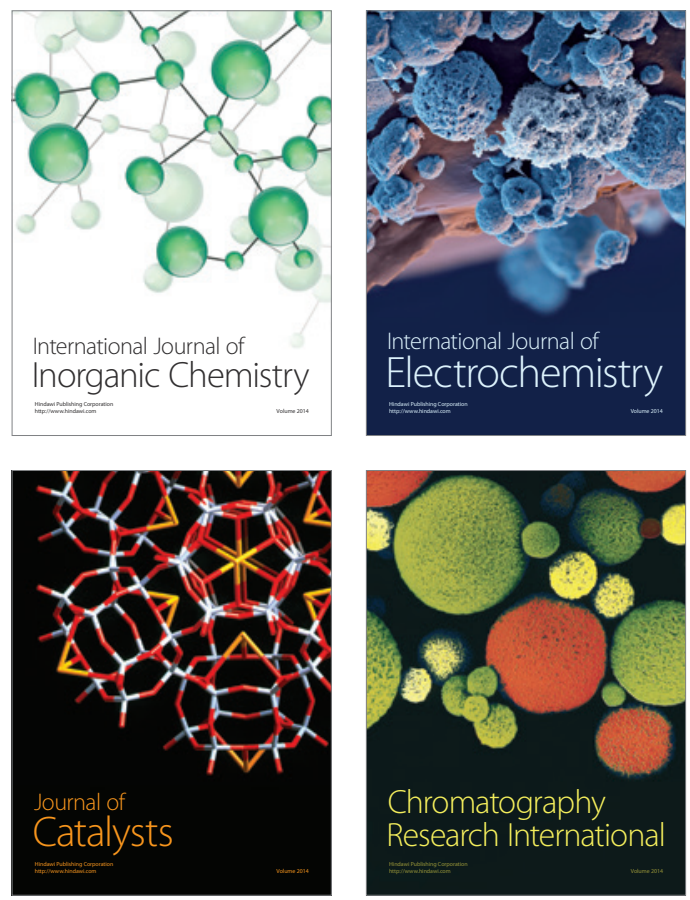
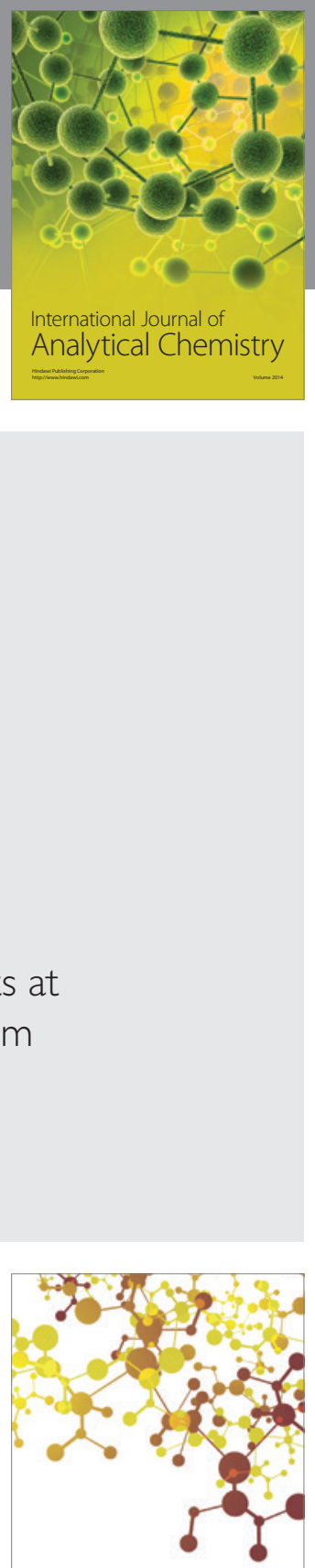

Journal of

Applied Chemistry
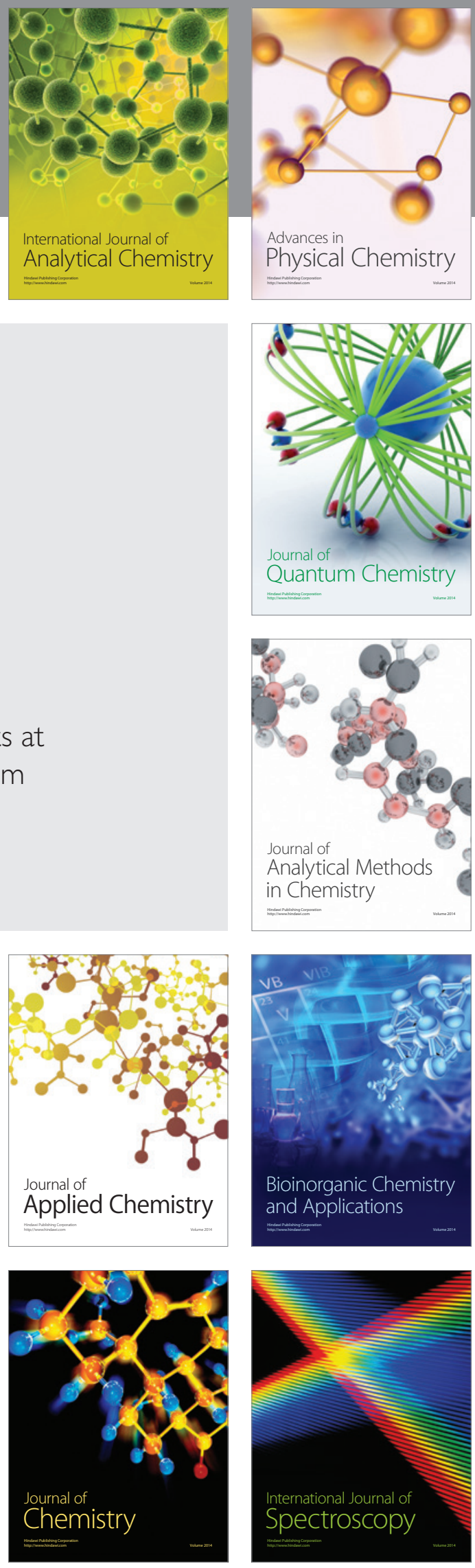